\title{
CO-AUTHORSHIP TRENDS AND COLLABORATION PATTERNS IN THE SLOVENIAN SOCIOLOGICAL COMMUNITY ${ }^{1}$
}

\author{
FRANC MALI ${ }^{2}-L U K A$ KRONEGGER ${ }^{3}-$ ANUŠKA FERLIGOJ ${ }^{4}$
}

\begin{abstract}
The article deals with some processes generating increases in research collaboration; one of the most characteristic tendencies of modern science. The major empirical focus is the increasing tendency to co-authorship in sociological publications in Slovenia. Bibliometric analyses, based on two joint national research information systems (SICRIS and COBISS), show the amount of coauthored publications in the field of sociology have increased over the last two decades. Blockmodeling of co-authorship networks in sociology has shown that sociologists who are not systematically tied to strongly connected and wellestablished research groups produce the best scientific publications in their field.
\end{abstract}

KEYWORDS scientific co-authorship, sociology in Slovenia, blockmodeling, scientific excellence, science evaluation

1 This work was supported in part by the Slovenian Research Agency (PJ5-2101). The authors wish to thank Irene H. Fieze and Patrick Doreian for their helpful comments and suggestions.

2 Dr. Franc Mali is Professor of Epistemology and Sociology of Science at the University of Ljubljana, Faculty of Social Sciences; e-mail: franc.mali@fdv.uni-lj.si; Phone: +386 15805 306; Kardeljeva pl. 5, SI-1000 Ljubljana, Slovenia.

3 Luka Kronegger is a doctoral candidate at the Faculty of Social Sciences, University of Ljubljana; e-mail: luka.kronegger@fdv.uni-lj.si; Phone: +386 15805 258: Kardeljeva pl. 5, SI-1000 Ljubljana, Slovenia.

4 Dr. Anuška Ferligoj is Professor of Statistics at the Faculty of Social Sciences, University of Ljubljana; e-mail: anuska.ferligoj@fdv.uni-lj.si; Phone: +386 15805 281: Kardeljeva pl. 5, SI-1000 Ljubljana, Slovenia. 


\section{INTRODUCTION}

The goal of this paper is to present some characteristics of trends in coauthorship patterns for sociological publications in Slovenia. Co-authorship is a prominent indicator of collaboration in academic science (Glaenzel et al. 2004; Katz et al. 1997). In the past, several bibliometric approaches (including co-authorship studies, co-citation analyses and co-word analysis) have been developed to analyze collaborations in science. Co-authorship networks and citation networks are useful for studying scientific collaboration and influence. In the co-authorship network, the network nodes represent authors connected by an undirected line if they have co-authored one or more publications. For a citation network, the network nodes are papers, and the links between them are citations represented by asymmetric lines. If science citation networks are the best bibliometric indicator to depict the whole structure of scientific knowledge, then co-authorship networks are the best bibliometric indicators for depicting the various patterns of collaborations in the academic scientific disciplines (Newman 2001).

Actually, the most characteristic tendency of modern science is intensification in scientific collaboration. Given this, scientific co-authorship characterizes the social and cognitive dynamics in modern science very well. Regardless of the level and the type of analysis, the concept of collaboration in science is understood as a process based on knowledge-sharing as well as facilitating the achievement of common goals. The phenomenon has been extensively studied and reviewed in bibliometric and sociological studies over the last few decades (see, for example, Pyka et al., 2009 and Shrum et al. 2007). However, there has not been a detailed analysis of the dynamics of co-authorship networks. The paper ${ }^{5}$ provides such an analysis. Here, we focus attention only on temporal trends of co-authorship in sociology. Coauthorship collaborations, formed in the Slovenian sociological community through time, are best presented through social networks that were established and have changed over time.

Co-authorship networks can be classified in several ways (Rogers et al. 2001; Shrum et al. 1988): (1) according to the units of the analysis given, the actors are represented by nodes - including individuals, teams of researchers, and R\&D organizations; (2) according to the type of information used to develop the links between nodes - this might consist of interactions or information

5 The authors of this paper, together with Patrick Doreian, Hajdeja Iglič, and Blanka Groboljšek form a research team studying the dynamics of co-authorship networks of four scientific disciplines - biotechnology, mathematics, physics, and sociology - in Slovenia. 
sharing or could be based on people's positions in a social hierarchy; and (3) according to the institutionalized domains to which the authors belong (with an emphasis on intra-organizational links between authors or interorganizational links between them). Our focus is on bibliometric networks featuring authors (item 1) and intra-organizational links among authors (item 3 ). We adopt a positional approach to analyze the locations of individuals in terms of their positions in networks. The authors we consider here belong to the field of sociology. We use blockmodeling (Doreian et al. 2005) to reveal the fundamental structure of co-authorship networks in sociology to identify clusters of authors having similar co-authorship ties with the other authors. Kronegger et al. (2010) used blockmodeling to analyze the structure of co-authorship networks through time for four scientific disciplines. One was sociology. For each discipline, they identified clear core-periphery structures with small multiple cores, comprised of scientists co-authoring with all, or most, colleagues in their core, a large semi-periphery made up of co-authoring authors with no systematic patterns of collaboration, and a periphery of authors not co-authoring with other scientists within the same field in Slovenia. Comparison of the delineated blockmodels through time showed that a clear core-periphery structure was not always present in coauthorship networks at early time periods. Here, we consider the stabilized core periphery blockmodeling structure of the co-authorship network of Slovenian sociologists for the time interval 2001-2005.

Our interest is also in examining the potential impact of some external (policy) factors which could stimulate or inhibit co-authorship in sociology in Slovenia. Research dealing with co-authorship in science rarely addresses such important issues as what national R\&D evaluation systems or national R\&D policies entail for co-authorships in science (Rogers et al. 2001). Our assumption is that to understand communication patterns within any scientific discipline (for example, co-authorship and publication behavior), it is necessary to include the role of external factors in a broader interpretative framework. The influence that external factors exert on research activity and its evaluation is mediated by the R\&D policy which directs research in certain ways. In small scientific communities, such as the community of sociologists in Slovenia, it is expected that the national R\&D policy will encourage an R\&D evaluation system that directs scientists towards internationalization (Mali et al. 2010). It is expected that scientists produce more successful scientific results when they join their domestic scientific efforts to scientific efforts from abroad. Having an international publishing orientation is important, and even necessary, for small scientific communities. Visibility, one precondition for attractiveness, can be created by publishing internationally. The most open 
scientific communities, internationally, even in so-called "book-publishing disciplines" such as humanities and social sciences, are characterized by decreases in publication frequency in national languages (see, for example, Aalotojarvi et al., 2008 and Hicks, 2004).

The paper is organized as follows: Conceptual issues are presented in the next section together with some hypotheses based on the literature and a description of this study. This is followed by a section describing our data as they were obtained from the SICRIS and COBISS data bases, two centralized and standardized bibliographic databases accessible to all scientists in Slovenia. In the next two sections, the results of our empirical analysis of trends and co-authorship patterns in sociology in Slovenia are presented and discussed. Given the longitudinal character of these trends, graphical presentations are preferred. In the next section, co-authorship trends are described in the form of blockmodels presenting the main types of co-authorship patterns in sociology in Slovenia for the period 2001-2005.

\section{CO-AUTHORSHIP AS AN INDICATOR OF A STRUCTURAL SHIFT IN THE COLLABORATIVE FORM OF MODERN SCIENCE}

Co-authorship in science is not the only form of scientific collaboration. De Hann (1997) has recommended six indicators to measure collaboration between social scientists: co-authorship, shared editorship of publications, shared supervision in $\mathrm{PhD}$ projects, writing research proposals together, participation in formal research programs, and shared organization of scientific conferences. As this list implies, there are many cases of scientific collaborations which do not result in co-authored publications (Katz et al. 1997; Melin et al. 1996; Laudel 2002). Laudel (2002) reports that about half of scientific collaborations are invisible to formal communication channels, either because they do not result in co-authored publications nor do they receive formal acknowledgments in scientific texts.

Price (1963) was an early advocate of the use of the co-authored publications as a measure of scientific collaboration. We concur and argue that formal coauthorship is the most active form of collaboration between researchers, and, for this reason, may be the best indicator of structural shifts in modern science (Rodriguez et al. 2008). It is interesting that in the history of science the collective efforts of many people to produce a publication cannot be counted as collaborative research. Collaborative research may designate research that results in co-authored publications, but according to Wray (2006), we can talk 
about collaborative research only when credit and responsibility are shared. Wray used an example from the history of science to point out the difference between collective and collaborative research: early modern chemistry (conducted in Robert Boyle's laboratory) was the result of the collective efforts of many people. But because Boyle insisted that he was in charge of the scene and all operations that took place in his laboratory, the activities should be described as collective, but not collaborative research. The scientific credit and responsibility rested with only one person in this situation so it was not a collaborative activity and no co-authorships were involved.

There has been tremendous growth in the number of, and overall percentage of, co-authored publications in all fields of science. The first coauthored scientific paper was published in 1665 (Lukkonen et al. 1992). The number of co-authored publications has increased ever since, first slowly, then dramatically in the second part of $20^{\text {th }}$ century and at the beginning of $21^{\text {st }}$ century. Bibliometric analyses have shown a continuous increase in the number of co-authored publications in nearly all scientific disciplines. These collaborations have occurred both within and across countries and regions within countries (see Rodriguez et al. 2008; Glaenzel et al. 2004 and Wray 2002). Beside bibliometric studies of scientific collaborations, there are also qualitative narrative studies about these scientific collaborations (e.g. Knorr-Cetina 1999). These types of case studies overcome some limits of bibliometric research but have several deficiencies of their own. For example, they may have more heuristic than explanatory value, since formal statistical procedures cannot be conducted, and samples are necessarily small. Here, the focus of our interest is strictly bibliometric while recognizing that narrative analyses could provide additional interpretive information.

Bibliometric studies of co-authored publications in science suggest that a large number of possible factors contribute to collaborations taking place. Since inclusion of all possible contributing factors is impossible, most of these analyses deal with three sets of factors believed to be the most important in explaining the increase of the co-authored publications: economic, cognitive, and social factors. Economic factors include the availability and form of resources including the massive funding of modern science ("big science"). Cognitive factors have driven the historical increase in specialization in science and now influence collaborative efforts across specialties. Beside the economic and cognitive factors, intra-scientific social factors, especially the changing communication patterns and increasing mobility of scientists, are also influencing collaboration through co-authored publications (Glaenzel et al. 2004; Beaver 2001; Katz et al. 1997; Beaver et al. 1978). The relative importance of these factors varies depending on the theoretical perspective 
of the authors studying co-authored publications and on the level of the analysis.

The benefits of collaborations through co-authored publications can be expressed in terms of both research inputs and outputs. One major benefit occurs when people with different skill sets work together and this increases the overall skill level of the team of collaborators. Recently, many arguments have been advanced to support the claim that the most important value of collaboration lies in the enhancement of epistemological authority. Included are arguments supporting the thesis that co-authored publications, because of the scientific collaboration involved, have greater epistemic authority than research performed by single individuals (Beaver 2004; Wray 2002). The epistemological advantage of scientific collaboration is that it confers the benefits of inter-subjective verifiability. Widely used in the social studies of science, this concept means the ability of researchers to validate scientific truth while allowing truth to change following new empirical results. In philosophy of science terms, collaborative research tends to merge the context of discovery and the context of justification. The context of discovery includes the factors leading researchers to advance hypotheses, while the context of justification includes the empirical scientific verification of the hypothesis (Popper 1959). At the same time, scientific collaboration should reduce uncertainty in the process of doing scientific work. Scientific collaboration can also be considered as a means for the enhancement of scientific visibility and productivity. For example, publications written by multiple authors tend to be relatively well cited. Those scientists who are involved in co-authored publications tend to have stronger citation records than those who do not have co-author publications (see Haslam et al. 2009; Persson et al. 2004; Wuchty et al. 2007). The benefit of scientific collaboration is seen particularly in the case of international scientific publications: many bibliometric analyses have shown that scientific articles stemming from international collaborations are cited more frequently, on average, than scientific articles produced within national collaborative projects (Hoekman et al. 2010). Although opposite views also exist $t^{6}$, the more supported position is that there is a strong positive correlation between co-authorship, scientific productivity and scientific impact (scientific impact measured through citation records).

6 It is also true that some bibliometric analyses found a negative relationship between increasing numbers of authors and higher citation impact (e.g., Rigby 2005). The explanation for these rare cases is that while research is carried out within larger networks where researchers may benefit from a more general rather than a more specific collaboration, some researchers may publish their important work in single-authored papers in order to enhance their reputations. 
We are aware that scientific collaboration in large scientific projects does not always provide positive benefits for those involved. Two possible negative consequences are noted but not extensively discussed in the literature. One is the lack of motivation for some scientists working in the large collaborative structures. Also, the cost of scientific collaboration is rising because of how the reward system in science works (Zuckerman et al. 1973; Wray 2006). It follows that scientists who work collaboratively may be concerned about getting adequate credit (symbolic capital) for their contributions to the project. In classical sociology of science, success in science depends to some extent on scientists getting credit for the work they produce. The recognition that scientists get from their peers for making a scientific discovery (an important scientific innovation) is a key motivation for scientists.

The second negative effect of working in large collaboration structures can be a loss of trust among scientists. Scientific trust is based on confidence in the abilities and efforts of collaborators, as well as on inter-personal relationships among them. Particularly in large collaborations among scientists in different institutions and across national boundaries, it may be difficult to truly know how much each individual contributes to the overall project. In any formal publication, only a subset of those involved at some level are likely to be included as formal co-authors. Those who are excluded may feel violated or unappreciated by those who prepared the publication and decided who to include as co-authors. This can lead to the excluded group losing confidence and trust in the overall project and in their fellow scientists. These processes were nicely described in the case of the Large Hadron Collider (LHC) program at CERN. This program, which began in 2008, includes large experimental projects such as ATLAS (with 2000 collaborators) and ALICE (with 1000 collaborators). Because of the very large size of the collaborations, there are growing issues of who is responsible for the integrity of the research project, of how to organize the evaluation of the individual contributions to the common research result, and of how to organize the final publication of the research results (Braun-Munzinger 2009). Partially because of these particular projects, there has been an increase in efforts to propose new rules for publication of scientific results in the field of experimental partial physics. The proposals for change, which seek to extend traditional forms of publication activity to include short research notes, are at least partially intended to acknowledge the efforts of additional scientists. These changes have already been adopted in some of the leading European physics journals such as European Journal of Physics A, Physical Letters B, and Nuclear and Particle Physics.

Bibliometric studies have looked at co-authorship trends in sociology, although most are restricted to the situation in the United States or to English- 
speaking countries. For example, Moody (2004) analyzed all English-language journal articles listed in Sociological Abstracts that were published between 1963 and 1999. Co-authored articles increased both as an overall percentage of all published articles (31\% in the early period compared to $38 \%$ in the later period) and as the average number of authors per co-authored paper (2.40 in the early period compared to 2.70 in the later). The same trends for American sociological articles were found by Hunter and Leahy (2008) in a study of the trends in collaboration over 70 years (from 1935 to 2005) in the top American sociological scientific journals. They found that, in the period from 1935 to 1940 , only $11 \%$ of the articles in the top sociological scientific journals were co-authored. In contrast, half of all articles for 2000 to 2005 were coauthored. This dramatic increase in co-authorship among sociologists was consistent with findings for other fields of social science, including political science (Fisher et al. 1998) and marketing (Brown et al. 2006). There are also some comparative bibliometric analyses comparing co-authorship patterns across countries. Pontille (2003) studied trends in American and the French sociological journals between 1960 and 1995. American sociological articles were different from the French articles at two levels: (1) American papers were more often co-authored, and (2) the number of authors per article was larger for the American papers in all periods reviewed. French sociological articles were mostly co-authored by two authors. The American sociological articles were mostly co-authored by between three and five authors per article. Even so, the intensity of collaborations in the sociology was low compared to the fields of natural science.

\section{THE PRESENT STUDY AND HYPOTHESES}

For the research described, we considered first the co-authorship of sociological publications in Slovenia from 1986 to 2005. The Slovenian situation merits attention for two reasons: (1) it is a small country with smaller scientific communities, and (2) it has very special historical roots. By looking at Slovenia, one can see if the trends reported in the U.S. and Western Europe also apply well to another region. Despite the differences regarding Slovenia, we expect to find similar trends in Slovenian co-authorship as have been found in other countries because science has properties independent of national features.

Beaver (2001) reported that over the past few decades, the structure of modern scientific research has been gradually become more and more similar throughout the world. Scientific research is increasingly carried out in 
formalized and hierarchical types of scientific organizations. Such convergence should also have implications for patterns of co-authorship in science. For example, Moody (2004) has identified three distinct collaboration structures within sociology in the United States. One model is the small-world model. Within this collaborative structure, the level of local clustering is high, and the average number of steps between actors is small. The second model is the scale-free model where prominent scientists are responsible for connecting the network. This model is organized on the principle of preferential attachment. Preferential attachment is a process in which some quantity, typically some form of wealth or credit, is distributed among a number of individuals or objects according to how much they already have, so those who are already wealthy receive more than those who are not. Scientists highly visible in their field through publications are preferred $^{7}$ as co-authors by others. The third model represents a collaborative structure where ties are distributed evenly across the whole (disciplinary) network. Namely, previous social network analyses have already shown that co-authorship ties in single disciplines are not necessarily socially cohesive. They consist of a number of collaborative groups of varying size - some interconnected, others isolated from all others (e.g. Newman 2004, 2001). Within these various groupings, some scientists play a primary role while others have a secondary one. Some scientists connect groups in loose collaborative networks and some scientists play both roles. Especially in sociology, a low-consensus discipline, it is reasonable to expect this third type of collaborative pattern.

We show (below) that Slovenian sociology, to some extent, follows the small-world model: there are groups of sociologists that are very connected in small groups, while others do not systematically collaborate with others. The next research question is whether the small-world structure of scientific collaboration in Slovenian sociology encourages or discourages the internationalization of publication activity. Is the publication strategy of sociologists included in the small-world structures more oriented to parochial scientific reports or publications in the Slovenian language or to publication in international peer reviewed journals?

Hypothesis 1: In Slovenian sociology, there has been an increase in the number of co-authored publications in the last two decades.

Hypothesis 2a: There is a small-world collaborative pattern in Slovenian sociology.

7 In the case of science, the principle of preferential attachment is often seen as the effect of »cumulative advantage« or, less correctly, the "Matthew effect". 
Hypothesis 2b: The presence of a small-world structure in scientific collaboration in Slovenia creates a barrier for stronger internationalization of the field.

Operationally, those Slovenian sociologists who form part of the smallworld structure publish less in international peer reviewed journals than the sociologists outside this small-world structure.

\section{DATA}

Our data sets were obtained from: (1) the Current Research Information System (SICRIS) which includes information about all active researchers registered at the Slovenian Research Agency (including education, positions and employment of researchers, information on the research groups and the institutions as well as information on both the projects and programs involving Slovenian researchers) and, (2) the Co-operative On-Line Bibliographic System \& Services (COBISS). Both systems are interconnected and are mutually maintained by the Institute of Information Science in Maribor, Slovenia (see http://www.izum.si). As a result, there is a complete bibliography available for each researcher included in the SICRIS database.

All researchers registered to work in sociology in Slovenia who were in SICRIS in September 2008 are included in this study. Collaboration between the researchers is operationalized by co-authorship of publications. A link between two researchers is measured by their co-authorship of relevant scientific contributions. The relevancy (or merit) of their contributions is defined by the evaluation system of overall scientific excellence of the social scientists, executed by the Slovenian Research Agency. Basic quantitative indicators used here for the evaluation of contributions are: scientific articles in the journals indexed by Web of Science (SSCI); scientific articles in the journals not indexed by the Web of Science database, but indexed by an international bibliographical database specialized in social science disciplines; the scientific articles in other Slovenian scientific journals listed by the national research agency; and scientific monographs or chapters in monographs issued by international or national (scientific) publishing houses. From 2000 onwards, the list of basic indicators was extended to include the authorship of large national corpuses of data (e.g. data from public opinion polls).

The first part of the empirical analysis was performed on the publications of 117 Slovenian sociologists who, in the period from 1986 to 2005, published 2880 publications. The second part focused on the period from 2001 to 2005 and includes 1291 publications of 116 sociologists. 


\section{RESULTS AND DISCUSSION}

To study the trend in collaboration and co-authorship in Slovenian sociology, we used two measures: the proportion of co-authored publications and the mean number of authors per publication. Time series of the percentages of single authored and co-authored publications of Slovenian sociologists over the period from 1986 to 2005 are presented in Figure 1. Co-authorship data is presented by the percentage of publications co-authored with researchers within sociology, the percentage of publications co-authored with Slovenian researchers from other disciplines, and the percentage of the publications coauthored with authors who are not part of Slovenian scientific system (i.e. are not registered at national research agency or come from another country). For each time series the trend was obtained by fitting the locally weighted scatter plot smoothing (LOESS) curve (Cleveland 1979). The results support the first hypothesis of increasing percentages of all three types of co-authorship publications. The percentage of single authorship publications did not decrease in the first 10 years but did decrease over the last ten observed years.

Figure 1 Single authored vs. co-authored publications from 1986 to 2005 of Slovenian sociologists with LOESS fitted trend curves

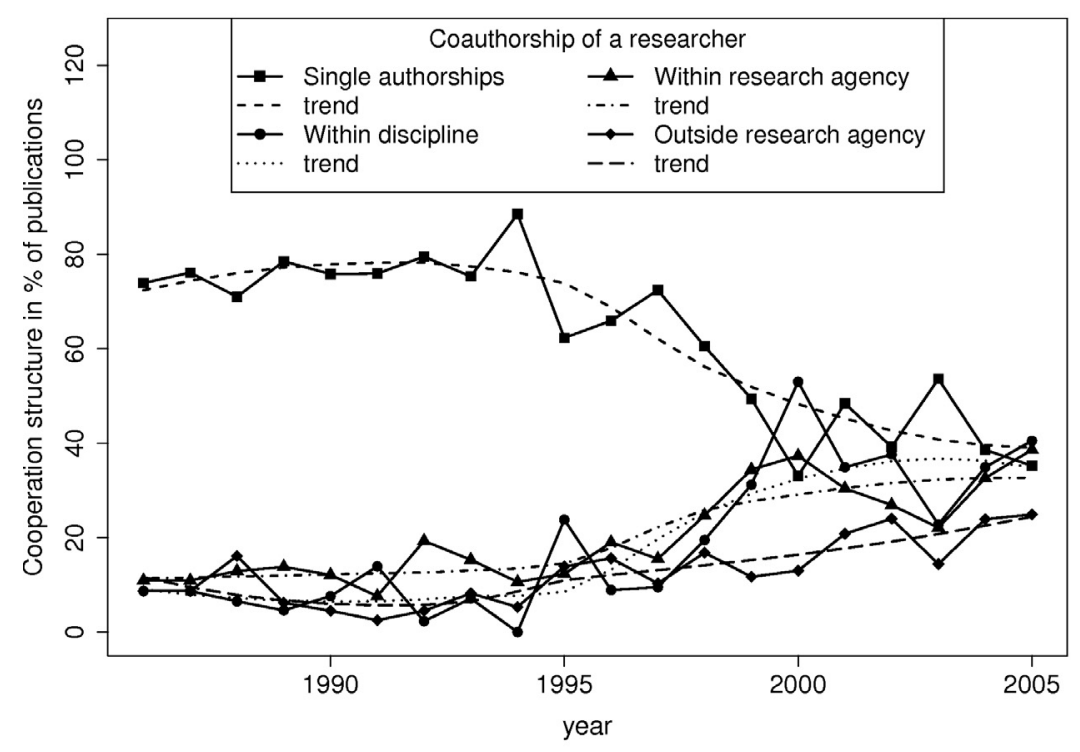


The trend of the mean number of authors per publication also shows an increase over time. In the years 1998 and 1999 several monographs with an extremely large number of co-authors were coded into the information system and produced the non typical jump in the time series (see Figure 2).

Figure 2 Mean number of authors per publication from 1989 to 2005 of Slovenian sociologists with LOESS fitted trend curves

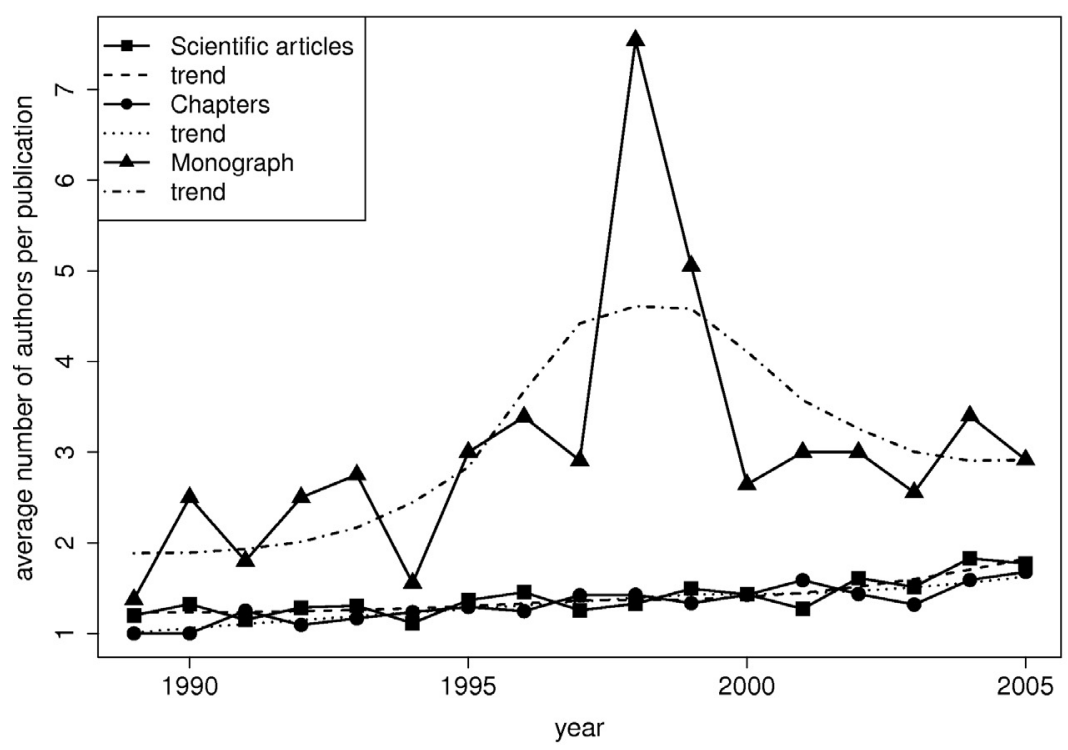

The trends presented in Figures 1 and 2 show increasing co-authorship in Slovenian sociology over time and are in accordance with the production of new knowledge in science. In the last two decades, new concepts about changes in the organization of scientific research in sociology have been constructed (see Nowotny et al. 1994; Ziman 2000). These new concepts are in many ways consistent with the idea of 'big science' introduced by Price (1960). The idea of 'big science' emphasized more regulated research work in scientific teams, massive infusion of funds from the state, the involvement of external stakeholders in directing R\&D goals and last, but not least, the use of large statistical datasets and corpuses in science production. In the new mode of knowledge production there is no difference between hard and soft sciences. Through utilization of complex empirical surveys, already known from other scientific fields, in social sciences, the need for collaboration in 
all phases of the research work has strongly increased. Price et al. (1976) have provided an elaborated scheme of collaboration patterns in the phase of publication activities). The following categories of collaborators in science were introduced: 'continuants', 'transients', 'newcomers' and 'terminators'. 'Transients' are authors who publish in a given year, but not before nor afterwards, 'newcomers' are authors who publish in and after a given year but never before, 'terminators' publish before and in the given year but never after, and 'continuants' publish before, in and after the given year. This terminology is in line with that used by Newman (2004) regarding the structure of scientific collaboration.

To test the second hypothesis about the presence of the small-world structure in co-authorship networks in sociology in Slovenia and how this affects the internationalization of the field, we used generalized blockmodeling (Doreian et al. 2005). Kronegger et al. (2010) used blockmodeling to delineate the structure of the Slovenian co-authorship networks of scientists for four selected scientific disciplines (including sociology) over four time intervals. One result is that scientific collaborations consolidated into a typical coreperiphery structure over time.

Figure 3 Blockmodeling structure of the sociological co-authorship network in years 2001-2005

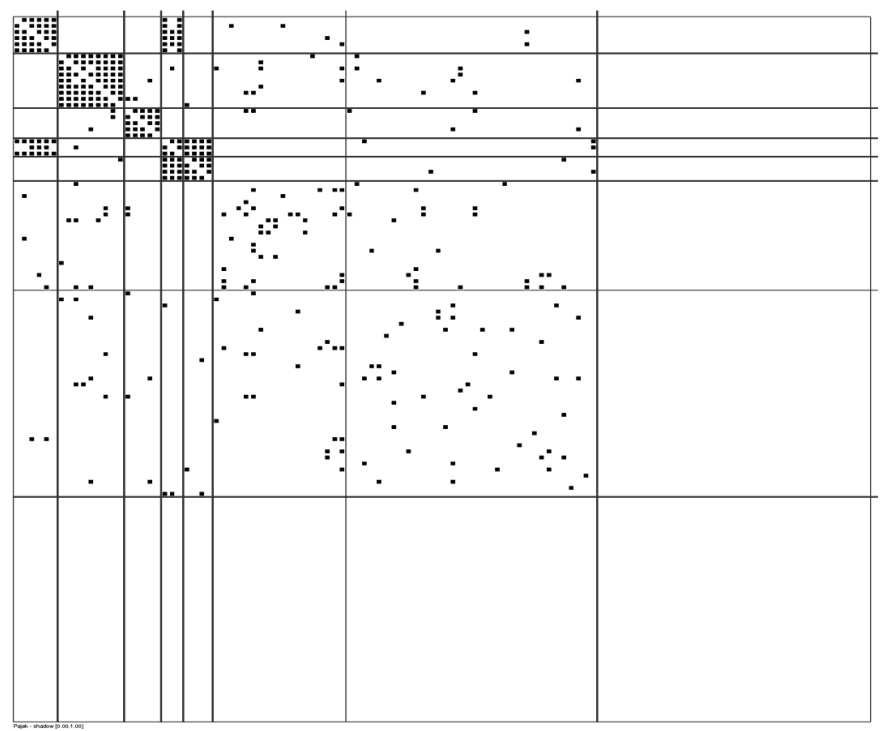


Figure 3 presents the core-periphery structure of the co-authorship network for 116 Slovenian sociologists for 2001-2005. There are five core (smallworld) clusters (sociologists within each of the cores collaborate with each other), a semi-periphery cluster (each sociologist in this cluster is co-author with at least one other sociologist), and a periphery cluster of sociologists (having no co-authorship with the other sociologists in Slovenia).

The blockmodel structure in Figure 3 is obtained only from co-authorship ties inside the field of sociology in Slovenia. To test Hypothesis $2 b$ we have to operationalize the internationalization of the field. This was done by using the number of peer reviewed international publications and by including coauthorship ties outside of the sociology field in Slovenia. The hypothesis is that the core clusters are scientifically less excellent and that they collaborate less with the scientists outside the sociological field in Slovenia. This hypothesis has a subtle implication beyond the statement itself. To the extent that the hypothesis is correct, then the comparison group, in relation to the members in the small world part of the co-authorship network, is composed of Slovenian sociologists belonging either to the semi-periphery or to the periphery. Because the members of the semi-periphery are involved in coauthorship ties within the wider field, and co-authorship is associated with high quality and enhanced epistemological authority, these are the sociologists whose work will be scientifically more excellent. Moreover, the hypothesis implies that members of the semi-periphery, on average, collaborate with scientists outside the field of sociology in Slovenia more frequently.

First, we examine the members of the semi-periphery according to their publication characteristics and co-authorship with the scientists outside of Slovenian sociology. We do not claim that every member of the semi-periphery has these features. This implies that, if necessary, attention be paid to whether or not authors in the semi-periphery do produce high quality scholarly documents and publish more with international colleagues. The variables measuring the quality and international performance were standardized and Euclidean distances were computed. We performed a cluster analysis (using the Ward agglomerative method) for the computed dissimilarities across sociologists in the semi-periphery. The resulting dendrogram is presented in Figure 4.

Two clusters are seen from the dendrogram. The averages of the included variables were calculated for each of the obtained clusters (semi-periphery 1 , the right cluster on the dendrogram and semi-periphery 2, the one on the left). Equally important, these averages were computed also for members of the of the core groups and for those in the periphery. Table 1 presents summaries of the four groups of sociologists. The two semi-periphery clusters separated 
by the lighter lines in Figure 3 are very different: the first cluster has above average means on all variables considered, especially number of articles and monographs published in English and articles in journals with an impact factor (these are the most excellent scientists in the field of sociology in Slovenia). The second semi-periphery is very similar to the periphery by having low averages for all variables. The core clusters have the highest averages for chapters in Slovene and English monographs and rather high averages on coauthorship ties outside the Slovenian field of sociology.

Figure 4 Clustering of members of semi-periphery according to their performance and co-authorship outside the domestic discipline

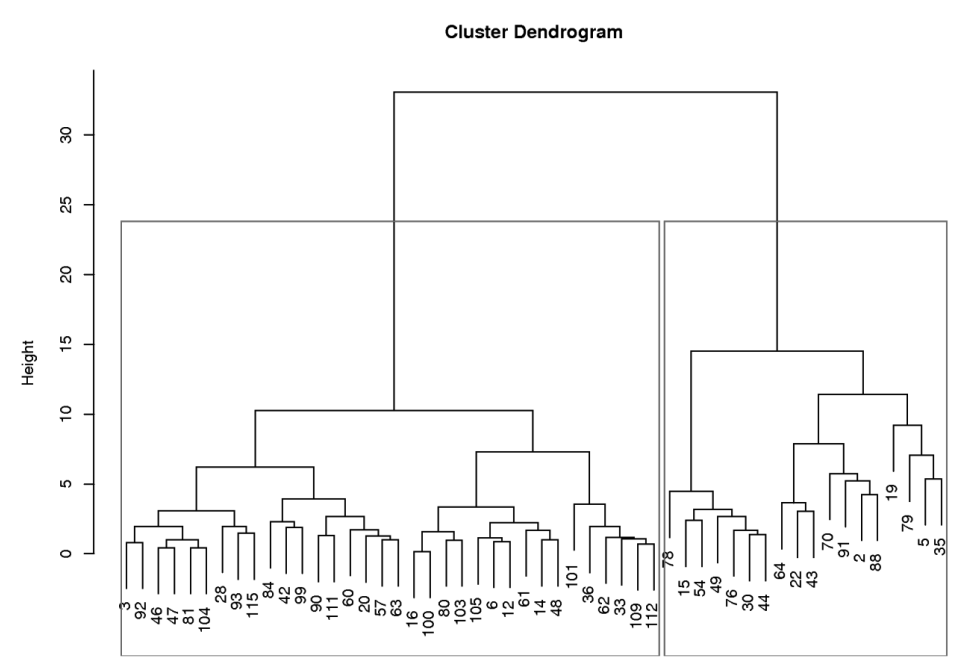

The blockmodeling results suggest that small-world model operates also in the case of Slovenian sociology. The core groups are quite stable with a cohesive structure and produced mostly chapters in monographs (probably systematic presentations of large research projects). In contrast, the scientists who are clustered into the first semi-periphery cluster have the highest average number of published articles, especially in journals with an impact factor, and monographs (also in English). Although our empirical analysis needs some additional statistical testing, we conclude that in the Slovenian case also there are well-known highly visible researchers (i.e. scientific "stars") who often collaborate with partners in the other disciplines and in the international scientific arena. However, they are less likely to work in very cohesive 
and long-range stable social networks. We note that the core clusters quite often collaborate outside the Slovenian sociology community, probably in international research projects. Therefore, Hypothesis $2 \mathrm{~b}$ receives only partial support.

Table 1 Means of standardized publication variables and co-authorship ties outside of sociology

\begin{tabular}{|c|c|c|c|c|c|c|c|}
\hline & \multicolumn{7}{|c|}{ Publications } \\
\hline & $\begin{array}{l}\frac{0}{20} \\
\frac{y}{0} \\
\frac{0}{E} \\
\frac{E}{2}\end{array}$ & 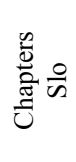 & 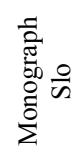 & 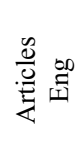 & 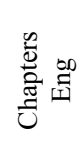 & 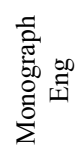 & 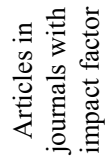 \\
\hline cores & -0.35 & 0.64 & .30 & -0.02 & 0.81 & 0.28 & -0.12 \\
\hline $\begin{array}{l}\text { semi- } \\
\text { periphery } 1\end{array}$ & 0.79 & 0.41 & 0.77 & 1.18 & 0.52 & 1.12 & 1.12 \\
\hline $\begin{array}{l}\text { semi- } \\
\text { periphery } 2\end{array}$ & -0.13 & -0.17 & -0.24 & -0.21 & -0.40 & -0.39 & -0.23 \\
\hline periphery & -0.02 & -0.51 & -0.38 & -0.37 & -0.47 & -0.39 & -0.25 \\
\hline
\end{tabular}

\begin{tabular}{|c|c|c|}
\hline & \multicolumn{2}{|c|}{ Co-authorships outside the discipline } \\
\hline & $\begin{array}{c}\text { within Slovenian } \\
\text { research community }\end{array}$ & $\begin{array}{c}\text { outside Slovenian } \\
\text { research community }\end{array}$ \\
\hline cores & 0.56 & 0.64 \\
\hline semi-periphery 1 & 0.63 & 0.25 \\
\hline semi-periphery 2 & -0.30 & -0.27 \\
\hline periphery & -0.44 & -0.34 \\
\hline
\end{tabular}

The results of our analysis are (partially) in accordance with the bibliometric analyses of Wagner and Leydesdorff (2005). Applying similar analytical tools, they pointed out that the growth of international co-authorship can be explained by the organizing principle of preferential attachment. Wagner and Leydesdorff's study suggested that the ability of an actor to join international collaboration structures depends on their attractiveness as a co-authorship partner. They further argued that, in modern science, the self-interest of individual scientists rather than some policy-related factors plays a much greater role in cooperation in the international scientific arena. 
Our empirical analysis can be explained in several ways. As is known from previous social network analyses (e.g., Said et al. 2008 and Granovetter 1973), more "open" networks, with many weak ties (or loose connections), are more likely to introduce new ideas and opportunities to their members than closed networks with many redundant ties. This holds also for collaboration across both disciplinary boundaries and national borders. If networks are generated according to the principle of preferential attachment, where young scientists work with research "stars", then we can not expect very long-range stable forms of cooperation. This is in accordance with some recent studies in the sociology of science which suggest that one of the major challenges of modern scientific production is to cross (sub)disciplinary boundaries. Scientists from different sub-disciplinary fields are usually trained in different departments, have different advisors, publish in different journals, and attend different conferences. The recent process of crossing (sub)disciplinary boundaries leads to mutual learning among scientists of different disciplinary backgrounds, facilitates easier communication and leads to greater creativity. Some of these tendencies were also identified in our empirical analysis of co-authorship networks of Slovenian sociologists.

\section{CONCLUSION}

The results of our analysis support our prediction of an increased trend in co-authorship in sociology in Slovenia from 1986 to 2005. This is not an earth shaking finding because such trends have been reported in many other studies. However, the results obtained by coupling blockmodel results to published quality and internationalization of research are the most interesting findings of our empirical study of co-authorship in Slovenian sociology. The foundation of our analysis was the blockmodeling structure obtained by Kronegger et al. (2010) with several core clusters (groups of sociologists that co-author strongly with each other), a semi-periphery (sociologists that have co-authored publications with the other sociologists in Slovenia but in non-systematic way) and a periphery (the members of this group have no co-authorship publications with the other sociologists in Slovenia). We noticed that the semi-periphery cluster is very heterogeneous according to publication performance. We therefore split it into two sub-clusters: one contained sociologists with very high publication performances and the other had those with very low performances. The second sub-cluster is very similar to the periphery cluster according to publication performance. We showed that sociologists in the first semi-periphery sub-cluster belong to the scientific 
elite in the sociological community in Slovenia and have the most excellent international scientific publications. It implies that the sociologists with the best international achievements tend to have co-authorship ties not with core group members but with others in the productive semi-periphery group - but in non-systematic way. The sociologists in the core clusters publish mostly with each other in quite closed circles and have also publications (mostly chapters in the monographs) with scientists outside the Slovenian sociology community, probably as results of international research projects.

The results of our analysis suggest that R\&D policy actors in Slovenia have to put more effort into increasing the orientation of all groups of sociologists in Slovenia to publish in high quality international scientific journals, especially for some of the long-term stable research groups (cores) who mostly follow a parochial publication strategy. The question if social scientists should mostly publish in excellent international peer reviewed journals or in domestic publications is still a matter of controversy in Slovenia. There are social scientists that worry that an international publication orientation could diminish the role and value of the Slovenian language in academic circles and have a negative impact on Slovenian society. Given our results, such controversy is out of date for small scientific communities such as Slovenia. Given the internationalization that has already occurred (and which drives up research quality), it seems that sociologists in Slovenia have to be oriented as much as possible to publishing in high quality international scientific journals as well as in Slovenian publications. Scientific communications confined to isolated and parochial communities of social scientists are no longer in a suitable environment for scientific excellence. Even so, it is also true that a local publication strategy (publications in the Slovene language) is connected with the necessity of mediating new knowledge into the local social environment.

Finally, we suggest that R\&D policy actors in Slovenia pay more attention to the creation of new $R \& D$ evaluation mechanisms to encourage wider collaborations among (social) scientists across institutions and disciplinary boundaries. This implies also that large amounts of resources not be confined to cores we have identified in the recent sociological co-authorship network. Relative to trends in the international scientific realm and in large national scientific communities, it appears that there remains a large group of sociologists in Slovenia who are committed to producing single author publications. Their numbers are declining as are the number of single authored publications. We view this as a positive trend that will raise the quality of scientific output in Slovenia. 


\section{REFERENCES}

Aaltojaervi, Inari - Ilkka, Arminen - Otto, Auranen - Hanna-Mari, Pasanen (2008), "Scientific productivity, web visibility and citation patterns in sixteen Nordic sociology departments", Acta Sociologica Vol. 51, No.1, pp. 5-22.

Beaver, Donald (2004), "Does collaborative research have greater epistemic authority?", Scientometrics Vol. 60, No. 3, pp. 399-408.

Beaver, Donald (2001), "Reflections on scientific collaboration (and its study): past, present, and future", Scientometrics Vol. 52, No. 3, pp. 365-377.

Beaver, D. - R., Rosen (1978), "Studies in scientific collaboration: Part I. The professional origins of scientific co-authorship", Scientometrics Vol. 1, No. 1, pp. 65-84.

Braun-Munzinger, Peter (2009), "Das Publikationsverhalten in Grosskollaborationen", in Stefan, Hornbostel et al., ed., Publikationsverhalten in unterschiedlichen wissenschaftlichenDisziplinen.BeitraegezurBeurteilungvonForschungsleistungen, Band 12, Berlin: Alexander von Humboldt.

Biagioli, Mario (1999), "Aporias of Scientific Authorship: Credit and Responsibility in Contemporary Biomedicine”, in M., Biagioli, ed., The Science Studies Reader, New York, London, Routledge, pp. 12-31.

Brown, Christopher - Chan L., Kam - Lai, Pikki (2006), "Marketing Journal Coauthorships: An Empirical Analysis of Coauthor Behaviour", Journal of Marketing Education Vol. 28, No. 1, pp. 17-25.

Cleveland, William S. (1979), "Robust Locally Weighted Regression and Smoothing Scatterplots", Journal of the American Statistical Association Vol. 74, No. 368, pp. 829-836.

Cronin, Blaise (2001), "Hyperauthorship. A Postmodern Perversion or Evidence of a Structural Shift in Scholarly Communication Practices?", Journal of the American Society for Information Science and Technology Vol. 52 , No. 7, pp. 558-569.

Doreian, Patrick - Vladimir, Batagelj - Anuška, Ferligoj (2005), "Generalized Blockmodeling", Cambridge, Cambridge University Press.

Glaenzel, Wolfgang - Andreas, Schubert (2004), "Analysing scientific networks through co-authorship", in: Henk F., Moed et al., ed., Handbook of Quantitative Science and Technology Research. The Use of Publication and Patent Statistics in Studies of S\&T Systems, Dordrecht, Boston, London, Kluwer Academic Publishers, pp. 257-276.

Granovetter, M. (1973), “The strength of weak ties”, American Journal of Sociology Vol. 78, pp. 1360-1380.

De Haan, J. (1997), “Authorship patterns in Dutch Sociology”, Scientometrics Vol. 39 No. 2, pp. 197-208.

Fischer, B.S. - C.T., Cobane-T.M.,Vander-F.T., Cullen (1998), "How many authors does it take to publish an article? Trends and patterns in political science", Political Science and Politics Vol. 31, No.4, pp. 847-856.

Haslam, Nick - Simon, Laham (2009), "Early-career scientific achievement 
and patterns of authorship: the mixed blessing of publication leadership and collaboration", Research Evaluation Vol. 18, No. 5, pp. 405-410.

Hicks, Diana (2004), "The Four Literatures of Social Science", in: Henk F., Moed et al., ed., Handbook of Quantitative Science and Technology Research. The Use of Publication and Patent Statistics in Studies of S\&T Systems, Dordrecht, Boston, London, Kluwer Academic Publishers, pp. 473-497.

Hornbostel, Stefan (1997), "Wissenschaftsindikatoren. Bewertungen in der Wissenschaft", Opladen, Westdeutscher Verlag GmbH.

Hunter, Laura - Erin, Leahey (2008), "Collaborative Research in Sociology: Trends and Contributing Factors", American Sociologists Vol. 39, No. 4, pp. 290-306.

Hoekman, Jarno - Frenken, Koen - Rober J.W., Tijssen (2010), "Research collaboration at a distance: changing spatial patterns of scientific collaboration within Europe", Research Policy Vol. 39, No. 5, pp. 662-673.

Katz, J.S. - B.R., Martin (1997), "What is research collaboration?", Research policy Vol. 26, No. 1, pp. 1-18.

Knorr-Cetina, Karin (1999), "Epistemic Cultures: How the Science Make Knowledgy", Harvard, Harvard University Press.

Kronegger, Luka - Anuška, Ferligoj - Patrick, Doreian (2010), "Collaboration Structures in Slovenian Scientific Communities", Quality and Quantity, in press.

Laband, David - Robert, Tollison (2000), "Intellectual Collaboration", Journal of Political Economy Vol. 108, No. 3, pp. 632-62.

Laudel, Grit (2002), "What do we measure by co-authorship?", Research Evaluation Vol. 11, No 1, pp. 3-15.

Lukkonen, Terttu - Olle, Persson - Gunnar, Siversten (1992), “Understanding Patterns of International Scientific Collaboration”, Science, Technology \& Human Values Vol. 17, No. 1, pp. 101-126.

Mali, Franc - Anton, Kramberger (2010), "An evaluation system of the science and international orientation of social scientists: The case of Slovenia", in: Ilona, Palne Kovacs et al. eds., Internationalisation of Social Sciences in Central and Eastern Europe. The catching up - a myth or a strategy? London, New York, Routledge, pp.192-215.

Melin, G. - O., Persson (1996), "Studying research collaboration using co-authorship", Scientometrics Vol. 36, No. 3, pp. 363-377.

Moody, James (2004), "The structure of a social science collaboration network: disciplinary cohesion from 1963 to 1999", American Sociological Review Vol. 69, No 2, pp. 213-238.

Newman, M.E.J. (2004), "Coauthorship networks and patterns of scientific collaboration", Proceedings of the National Academy of Science of the United States of America, 101, (Suppl. 1), April 6, pp. 5200-5205.

Newman, M.E.J. (2001), “The Structure of Scientific Collaboration Networks", Proceedings of the National Academy of Science of the United States of America, 98 (Suppl. 2), January 16, pp. $404-409$.

Nowotny, Helga - Peter, Scott - Michael, Gibbons (2001), “Re-Thinking Science. 
Knowledge and the Public in an Age of Uncertainty", London, Polity Press with Blackwell Publishers

Persson, O. - W., Glaenzel - R., Danell (2004), "Inflationary bibliometric values: the role of scientific collaboration and the need for relative indicators in evaluative studies", Scientometrics Vol. 60, No. 3, pp. 421-432.

Popper, Karl R. (1959), “The Logic of Scientific Discovery”, London, Hutchinson CO Publishers LTD.

Pontille, David (2003), "Authorship Parctices and Institutional Contexts in Sociology: Elements for a Comparison of the United States and France", Science, Technology \& Human Values Vol. 28 No. 2, pp. 217-234.

Price, D. J. de Solla (1963), "Little Science. Big Science and Beyond", New York, Columbia Press.

Price, D. J. de Solla - S., Guersey (1976), "Studies in Scientometrics. Part 1.Transience and continuance in scientific authorship", International Forum on Information and Documentation No. 1, pp. 17-24.

Pyka, Andreas - Andrea, Scharnhorst (2009), "Innovation Networks. New Approaches in Modelling and Analyzing", Dordrecht, Berlin, Heidelberg, Springer Verlag.

Rigby, John (2005), "Handcrafted by 16 men: The impact of single and multiple authorship in collaborative research networks", Research Evaluation Vol. 14, No. 3, pp. 199-206.

Rodriguez, Marko - Alberto, Pepe (2008), On the relationship between the structural and socioacademic communities of a coauthorship network, Journal of Infometrics Vol. 2, No. 3, pp. 195-201.

Rogers, Juan - Barry, Bozeman - Ivan, Chompalov (2001), "Obstacles and opportunities in the application of network analysis to the evaluation on R\&D", Research Evaluation Vol. 10, No. 3, pp. 161-172.

Said, H. Yasmin - Edward J., Wegman - Walid K., Sharabati - John T., Rigsby (2008), "Social network of author - coauthor relationships", Computational Statistics \& Data Analysis Vol. 52, No. 4, pp. 2177-2184.

Shapin, Steven (1994), "A Social History of Truth: Civility and Society in Seventeenth Century England", Chicago, Chicago University Press.

Shrum, W. - N., Mullins (1988), "Network analysis in the study of science and technology", in A., van Ran, ed., Handbook of Quantitative Studies of Science and Technology. Amsterdam, Elsevier, pp.107-133.

Shrum, Wesley - Joel, Genuth - Ivan, Chompalov (2007), Structures of Scientific Collaborations, Cambridge, London, The MIT Press.

Wagner, S. Caroline - Loet, Leydesdorff(2005), "Network structure, self-organization, and the growth of international collaboration in science. Research Policy Vol. 34, No.10, pp. $1608-1618$.

Wray, K. Brad (2006), "Scientific authorship in the age of collaborative research", Studies in History and Philosophy of Science Part A Vol. 37, No.3, pp. 505-514.

Wray, K. Brad (2002), "The Epistemic Significance of Collaborative Research", Philosophy of Science Vol. 69, No. 1, pp. 150-168. 
Wuchty, Stefan - Jones, Benjamin - Uzzi, Brian (2007), "The increasing dominance of teams in production of knowledge", Science Vol. 316, No. 5827 (18 May), pp. 1036-1039.

Ziman, John (2000), Real Science. What it is, and what it means, Cambridge, Cambridge University Press.

Zuckerman, Harriet - Robert, Merton (1973), "Institutionalized patterns of evaluation in science", in R., Merton, ed., The Sociology of Science: Theoretical and Empirical Investigations. Chicago, Chicago University Press. 